\title{
Ulinastatin protects the lungs of COPD rats through the HMGB1/TLR4 signaling pathway
}

\author{
WEI LIU ${ }^{1,2}$, ZHIGUANG LIU ${ }^{2}$, WEIDONG ZHANG ${ }^{2}$ and SHAOXI CAI ${ }^{1}$ \\ ${ }^{1}$ Chronic Airway Diseases Laboratory, Department of Respiratory and Critical Care Medicine, \\ Nanfang Hospital, Southern Medical University, Guangzhou, Guangdong 510515; \\ ${ }^{2}$ Department of Respiratory Medicine, Hunan Provincial People's Hospital, \\ The First Affiliated Hospital of Hunan Normal University, Changsha, Hunan 410005, P.R. China
}

Received December 26, 2016; Accepted February 12, 2018

DOI: $10.3892 / 01.2018 .9123$

\begin{abstract}
The present study aimed to investigate the protective mechanism of ulinastatin against lung injury. Rat models with chronic obstructive pulmonary disease (COPD) were used to provide guidance for the medical treatment of this disease. The rats were divided into three groups: A control group, a model group and an experimental group (each, $\mathrm{n}=10$ ). With the exception of the control group, all of the rats were prepared as models of COPD, using the composite molding method of smoking and intratracheal instillation of lipopolysaccharide. The rats in the model group all received a conventional treatment, while the rats in the experimental group received ulinastatin. A small animal lung function detector was used to examine lung function. The forced expiratory volume/sec (FEV) was negatively correlated with the protein expression levels of Toll-like receptor 4 (TLR4) and high mobility group box protein 1 (HMGB1). Real-time fluorescence quantitative polymerase chain reaction and western blot analyses were used to detect TLR4, MyD88 (myeloid differentiation factor 88), TRAF-6 (TNF receptor-associated factor 6), LOX-1 (lectin-type oxidized LDL receptor 1) and HMGB1 mRNA, along with their protein expression levels.
\end{abstract}

Correspondence to: Dr Shaoxi Cai, Chronic Airway Diseases Laboratory, Department of Respiratory and Critical Care Medicine, Nanfang Hospital, Southern Medical University, 1023 Shatainan Road, Baiyun, Guangzhou, Guangdong 510515, P.R. China

E-mail: caishaoxi1226@163.com

Abbreviations: TLR4, toll-like receptor 4; COPD, chronic obstructive pulmonary disease; FEV, forced expiratory volume/sec; HMGB1, high mobility group box protein 1; MyD88, myeloid differentiation factor 88; TRAF-6, TNF receptor-associated factor 6; LOX-1, lectin-type oxidized LDL receptor 1; LPS, lipopolysaccharide; RT-qPCR, reverse transcription-quantitative polymerase chain reaction; RT, reverse transcriptase; FVC, forced vital capacity; PEF, peak expiratory flow

Key words: chronic obstructive pulmonary disease, ulinastatin, high mobility group box protein 1, toll-like receptor 4
The lung function of rats in the model group was significantly decreased compared with in the control group $(\mathrm{P}<0.05)$. In the experimental group the lung function was significantly greater, when compared with in the model group; however, it remained lower than in the control group. The mRNA and protein expression levels of TLR4, MyD88, TRAF-6, LOX-1 and HMGB1 were significantly higher in the model group than in the control and experimental groups; however, levels in the experimental group were significantly higher when compared with in the control group $(\mathrm{P}<0.05)$. The TLR4 and HMGB1 expression levels were positively correlated in all groups, which indicated involvement of the HMGB1/TLR4 signaling pathway. The FEV was negatively correlated with the protein expression levels of TLR4 and HMGB1. Thus, the protective effect of ulinastatin in the lungs of rats with COPD is associated with changes in the HMGB1/TLR4 signaling pathway.

\section{Introduction}

Chronic obstructive pulmonary disease (COPD) is a common and chronic respiratory disease. The main feature of COPD is an incomplete irreversible airflow limitation, which is present in the progressive development of the disease. Furthermore, COPD is associated with an inflammatory reaction to harmful gases or particles in the lungs. A previous study has revealed that the incidence rate of COPD increases annually (1), and is expected to become one of the world's top three causes of pathogenic-associated mortality by 2020 (2). The latest epidemiological survey data revealed that the incidence rate of COPD among people aged $\geq 40$ in China has risen to $9.9 \%$ (3). This disease is a major threat to the health of China's residents, and is also ranked the top disease burden in China (4). A number of the symptoms of COPD can be controlled through drug treatments; however, there is no effective treatment available that can delay or reverse the disease course (5). Therefore, it is of vital importance for a novel effective treatment to be developed.

Ulinastatin is a type of broad-spectrum protease inhibitor (6). It has the ability to inhibit the activity of glycohydrolase, lipid hydrolase and protease through numerous pathways, as well as to restrain the excessive release of inflammatory mediators, including TNF- $\alpha$, IL- 6 and IL- 8 , thus reducing the tissue damage (6). A number of studies have revealed that ulinastatin 
may have the ability to prevent the development of acute lung injury, by inhibiting the release of inflammatory mediators (7-9); therefore, it is widely used in the clinical treatment of acute lung injury (10). The occurrence and development of COPD is closely associated with the inflammatory reaction, and the symptoms of the majority of patients are unable to be alleviated during the acute exacerbation of COPD. Ulinastatin has not been previously used in a study on its effects in COPD; therefore, this study used COPD rat models. The rats were given ulinastatin treatment, to determine whether it has a protective effect on lung injury in COPD.

The high mobility group box protein 1 (HMGB1) is distributed in the nuclei and cytoplasm of numerous different types of cells (11). In 1999, Wang et al (12) revealed for the first time, to the best of our knowledge, that HMGB1 is involved in sepsis, and can be considered an important inflammatory mediator. A number of previous studies revealed that ulinastatin could inhibit the release of the inflammatory mediator HMGB1 $(8,13,14)$, and, therefore, it could be associated with COPD due to the high expression of HMGB1 in COPD (15). Toll-like receptor 4 (TLR4) is the receptor for HMGB1; the pro-inflammatory role of HMGB1 is closely associated with the TLR4 signal transduction pathway $(16,17)$. When the HMGB1/TLR4 signaling pathway is activated, HMGB1 binds to and activates TLR4. The activated TLR4 then binds with the TLR4 receptor on myeloid differentiation factor 88 (MyD88) with the aid of MD-2. MyD88 activates IRAK through its death domain, which then activates tumor necrosis factor receptor-associated factor (TRAF6) (18). TRAF6 can activate the nuclear factor $\kappa \mathrm{B}(\mathrm{NF}-\kappa \mathrm{B})$ signaling pathway, mediated by the downstream associated factors. This causes the upregulation of lectin-type oxidized LDL receptor 1 (LOX-1), mediating the inflammatory response (18). A previous study revealed that knocking out the TLR4 gene using small interfering RNA could alleviate the inflammatory reaction induced by HMGB1 (19). In the present study, the expression of key molecules associated with the HMGB1/TLR4 signaling pathway was evaluated in lung tissues of COPD rats, in response to treatment with ulinastatin. The mechanism of action of this drug was partially explored, in order to provide a theoretical basis for the effect of ulinastatin in the clinical treatment of COPD.

\section{Materials and methods}

Instruments and reagents. Lipopolysaccharide (LPS) was purchased from Sigma-Aldrich (Merck KGaA, Darmstadt, Germany); mortar and grinding rods were purchased from Jiangsu Shunhe Teaching Instrument Co., Ltd. (Jiangsu, China); ulinastatin was purchased from Guangdong Techpool Bio-Pharma Co., Ltd. (Guangzhou, China); the RNA extraction reagent TRIzol ${ }^{\circledR}$ was purchased from Invitrogen (Thermo Fisher Scientific, Inc., Waltham, MA, USA), reverse transcription kit (cat no. 6110A), the fluorescence RT-qPCR kit (cat no. 639676) was purchased from Takara Biotechnology Co., Ltd. (Dalian, China); all primers were synthesized by Shanghai Shenggong Biological Engineering Technology Service, Ltd. (Shanghai, China); chloroform, isopropanol, DEPC water, anhydrous ethanol, agarose were purchased from Shanghai Shenggong Biological Engineering Technology Service, Ltd.; Nanodrop2000 Protein Nucleic Acid Analyzer was purchased from Thermo Fisher Scientific, Inc.; the agarose gel electrophoresis imaging system was purchased from Biometra $\mathrm{GmbH}$ (Göttingen, Germany); the $\mathrm{ViiA}^{\mathrm{TM}} 7$ fluorescent RT-qPCR machine was purchased from Applied Biosystems (Thermo Fisher Scientific, Inc.); the flexiVent animal lung function instrument was purchased from SCIREQ Inc. (Montreal, Canada); the RIPA cell lysate (cat no. 20101ES60) and PMSF were purchased from Shanghai Biyuntian Bio-technology Co., Ltd. (Shanghai, China); S-18KS handheld microelectromotive tissue homogenizer was purchased from Leptute Scientific Instruments (Beijing) Co., Ltd. (Beijing, China); the total protein extraction kit was purchased from BestBio, Co. (Shanghai, China); the Coomassie Brilliant Blue protein determination kit was purchased from Shanghai Majorbio Bio-pharm Technology Co., Ltd. (Shanghai, China); the SDS-polyacrylamide, PBST solution, vertical electrophoresis apparatus and GIS-2020D gel image analysis system were purchased from Sigma-Aldrich; superSignal ${ }^{\mathrm{TM}}$ chemiluminescence substrate was purchased from Thermo Fisher Scientific, Inc.; nitrocellulose membrane, developer, fixer and film were purchased from China Lucky Film Group Corporation (Baoding, Hebei, China); TLR4 (cat no. ab13556), MyD88 (cat no. ab2064), TRAF-6 (cat no. ab33915), LOX-1 (cat no. ab60178), HMGB1 (cat no. ab18256), GAPDH (cat no. ab8245) and Horseradish Peroxidase (HRP)-conjugated rabbit anti-mouse IgG secondary antibody (ab6728) were purchased from Abcam (Cambridge, MA, USA).

Preparation of the animal models. A total of 30 healthy, specific-pathogen-free, male adult Sprague-Dawley ${ }^{\circledR}$ rats with a weight range of 180-200 g, 2-3 months of age were provided by the Guangdong Medical Lab Animal Center (Foshan, China). The rats were housed at a temperature of $20-25^{\circ} \mathrm{C}$, a humidity of $50-65 \%$ a $12 \mathrm{~h} \mathrm{light/dark} \mathrm{cycle} \mathrm{and} \mathrm{given} \mathrm{free} \mathrm{access} \mathrm{to}$ food and water. The rats were fed adaptively for one week, and randomly divided into three groups: A control group, a model group and an experimental group, with each group containing 10 rats. The method of establishing a COPD rat model was as follows: At days 1 and 14, the rats were injected with $0.2 \mathrm{ml}$ $(200 \mu \mathrm{g})$ LPS solution $(1 \mathrm{~g} / \mathrm{l})$ in the trachea through a tracheal intubation under a 10\% chloral hydrate anesthesia (according to a $3 \mathrm{ml} / \mathrm{Kg}$ dose). Rats were then vertically rotated in order to uniformly distribute the LPS in the lung. Following on, the rats were placed in a homemade glass box in the morning of days 2-13 and days 15-28, where they continuously inhaled cigarette smoke for $1 \mathrm{~h} /$ day. The rats in the control group were injected with the same volume of saline through the trachea, but did not inhale any cigarette smoke. The rats in the model group received conventional treatments available for COPD, including expelling phlegm, improving ventilation and antibiotic regimens, whereas rats in the experimental group received 100,000 U/each time of ulinastatin intravenously twice a day for seven days. Upon completion, the lung function was detected using the small animal lung function detector. Following this, the rats were sacrificed after one week, and the lung tissues were removed and stored at $-80^{\circ} \mathrm{C}$ for subsequent experiments. The experimental program in this study was examined and ethically approved by the Laboratory Animal Ethics Committee.

RNA extraction and RT- $q P C R$ analysis. Total RNA in the lung tissue was extracted using a TRIzol ${ }^{\circledR}$ kit. The lung tissue was 
Table I. Forward and reverse upstream primers used in the present study.

\begin{tabular}{lll}
\hline Protein & \multicolumn{1}{c}{ Upstream primers, $\mathrm{F}$} & \multicolumn{1}{c}{ Upstream primers, $\mathrm{R}$} \\
\hline TLR4 & CGCTTTCAGCTTTGCCTTCA & CTCCAGAAGATGTGCCTCCC \\
MyD88 & GCTGACTTGGAGCCTGATTCT & ATGGGTGGGTGGGAGTAAA \\
TRAF-6 & AGAGGAATCACTTGGCACGG & TCTGCGTTTCCATTT TGGCG \\
LOX-1 & CCTCACCTGGAAGCTAAACG & CCTGCTCTTTGGATTTCTCG \\
HMGB1 & ATGGGCAAAGGAGATCCTA & ATTCATCATCATCATCTTCT \\
GAPDH & CTGAGCACTCTCCCTCACAATTC & GTGCAGCGAACTTTATTGATGGT
\end{tabular}

TLR4, Toll-like receptor 4; HMGB1, high mobility group box protein 1; MyD88, myeloid differentiation factor 88; TRAF-6, TNF receptor-associated factor 6; LOX-1, lectin-type oxidized LDL receptor 1; F, forward; R, reverse.

ground up in a mortar in a liquid nitrogen environment, then $1 \mathrm{ml} \mathrm{TRIzol}{ }^{\circledR}$ was added, followed by $200 \mu \mathrm{l}$ chloroform to extract the layers. The supernatant was transferred to another $1.5 \mathrm{ml}$ EP tube, to which $1 \mathrm{ml}$ isopropanol was added to precipitate the RNA. Using $1 \mathrm{ml}$ of $70 \%$ ethanol, the RNA was washed twice and then dissolved in DEPC water. The RNA purity and content detected using a protein nucleic acid detector (Coomassie Brilliant Blue protein determination kit). Subsequently, $1 \%$ agarose gel electrophoresis was conducted to identify the integrity of the RNA. Following this, $1 \mu \mathrm{g}$ RNA was used to synthesize cDNA via RT, using a Reverse Transcription kit (fluorescence RT-qPCR kit), according to the manufacturer's protocol.

In the reverse transcription reaction system a total volume of $10 \mu \mathrm{l}$ reaction mixture was used, including $1 \mu \mathrm{g}$ total RNA, $2 \mu 1$ of $5 \mathrm{X}$ reverse transcriptase buffer, $0.5 \mu \mathrm{l}$ oligo (dT) and Random Primer Mix, $0.5 \mu 1$ RT Enzyme Mix, $0.5 \mu \mathrm{l}$ RNase inhibitor, and supplemental $\mathrm{ddH}_{2} \mathrm{O}$ to bring the total volume up to $10 \mu \mathrm{l}$. The reaction conditions were as follows: $37^{\circ} \mathrm{C}$ for $15 \mathrm{~min}$ and $98^{\circ} \mathrm{C}$ for $5 \mathrm{~min}$. The cDNA produced was stored at $-20^{\circ} \mathrm{C}$ for later use. The cDNA was then used as a template, the fluorescence $\mathrm{RT}$-qPCR reaction system was set as follows: $5 \mu \mathrm{l}$ of $2 \mathrm{X} \mathrm{SYBR}{ }^{\circledR}$ Green Mixture, $0.5 \mu \mathrm{l}$ cDNA, $0.5 \mu \mathrm{l}$ Primer $\mathrm{F}(10 \mu \mathrm{M}), 0.5 \mu \mathrm{l}$ Primer $\mathrm{R}(10 \mu \mathrm{M})$ and $4 \mu \mathrm{ldd} \mathrm{H}_{2} \mathrm{O}$. The reaction conditions were set as follows: Pre-denaturing at $95^{\circ} \mathrm{C}$ for $10 \mathrm{~min}, 40 \mathrm{PCR}$ cycles of denaturing at $95^{\circ} \mathrm{C}$ for $15 \mathrm{sec}$, and annealing and extension at $60^{\circ} \mathrm{C}$ for $60 \mathrm{sec}$. The reactions were processed in a $\mathrm{ViiA}^{\mathrm{TM}} 7$ fluorescence RT-qPCR instrument using the $2^{-\Delta \Delta C q}$ method (20). Overall, three parallel samples were set as replicates for each experiment, with GAPDH as the internal control gene. The sequences of the specific primers are depicted in Table I.

Protein extraction and western blot analysis. The obtained lung tissues were added to $400 \mu \mathrm{l}$ RIPA cell lysate containing Phenylmethanesulfonyl fluoride (PMSF) (PMSF: RIPA=1:1,000) and homogenized in a homogenizer. After being placed on ice for $30 \mathrm{~min}$, the samples were centrifuged at $13,400 \mathrm{x} \mathrm{g}$, and centrifuge at $30^{\circ} \mathrm{C}$ for $4 \mathrm{~min}$. The supernatant was collected to obtain total lung tissue proteins. The proteins were quantified with a BCA Protein Quantitation kit, and the total protein was stored at $-80^{\circ} \mathrm{C}$ for later use. After the $6-12 \%$ gradient SDS-PAGE was prepared, $40 \mu \mathrm{g}$ protein samples were loaded for electrophoretic separation $(100 \mathrm{~V}, 4 \mathrm{~h})$. The protein gels were then placed into a transferring electrophoresis chamber, and transferred at $100 \mathrm{~V}$ for $1.5 \mathrm{~h}$ with the added transferring buffer. The transferred membranes were blocked for $2 \mathrm{~h}$ on a shaker at room temperature, in PBST containing 5\% skim-milk powder. After rinsing with PBST three times, the membranes were incubated at $4^{\circ} \mathrm{C}$ on a shaker with the primary antibody (1:500 dilution) solution. Following this, PBST was used to rinse the membranes for $30 \mathrm{~min}$; then diluted secondary antibody (diluted 1:10,000) was added, which was diluted with PBST containing $2.5 \%$ skimmed milk powder, and incubated at room temperature in a shaker for $60 \mathrm{~min}$. After using PBST to rinse another three times, the nitrocellulose membranes were evenly applied with the chemiluminescence reagent, and underwent exposure in a darkroom. The films were developed in developing reagent for $2 \mathrm{~min}$, rinsed, and then fixed in a fixing reagent for $2 \mathrm{~min}$. The films were further rinsed and hung to dry. The GIS-2020D Gel Imaging Analysis System was used to analyze the optical density of the protein bands of TLR4, MyD88, TRAF-6, LOX-1, HMGB1 and GAPDH. The relative protein expression intensity was defined as the optical density of the protein bands of TLR4, MyD88, TRAF-6, LOX-1 and HMGB1 compared with that of GAPDH.

Statistical analysis. SPSS 20.0 statistical software (IBM Corp., Armonk, NY, USA) was used for statistical analysis. Measured data were expressed as the mean \pm standard deviation. The counted data were expressed as the number of cases or percentage. The comparison between the control group, model group and experimental group was performed using the ANOVA. The comparison between the groups was performed using the Student-Newman-Keuls test. Pearson correlation analysis was used to analyze the correlation between the two sets of data that matched the normal distribution. Spearman correlation analysis was used to analyze the correlation between two sets of data that did not follow the normal distribution. $\mathrm{P}<0.05$ was considered to indicate a statistically significant difference.

\section{Results}

Effect of ulinastatin on lung function. As depicted in Table II, the rat lung function indexes, FEV and forced vital capacity 
Table II. Comparison of inspection results of rat lung function among the groups.

\begin{tabular}{|c|c|c|c|c|}
\hline Group & $\mathrm{FEV}_{0.3}(\mathrm{ml})$ & $\mathrm{FVC}(\mathrm{ml})$ & $\mathrm{FEV}_{0.3} / \mathrm{FVC}(\%)$ & $\operatorname{PEF}\left(\mathrm{ml} . \mathrm{s}^{-1}\right)$ \\
\hline Control group & $5.56 \pm 0.31$ & $6.68 \pm 0.43$ & $90.10 \pm 2.78$ & $36.78 \pm 3.89$ \\
\hline Model group & $3.89 \pm 0.32^{\mathrm{a}}$ & $4.71 \pm 0.39^{\mathrm{a}}$ & $74.24 \pm 2.31^{\mathrm{a}}$ & $26.16 \pm 3.12^{\mathrm{a}}$ \\
\hline Experimental group & $5.07 \pm 0.41^{\mathrm{a}, \mathrm{b}}$ & $6.11 \pm 0.45^{\mathrm{a}, \mathrm{b}}$ & $83.26 \pm 2.56^{\mathrm{a}, \mathrm{b}}$ & $32.48 \pm 3.26^{\mathrm{a}, \mathrm{b}}$ \\
\hline
\end{tabular}

${ }^{a}$ Model group compared with the control group, $\mathrm{P}<0.05$; experimental group compared with the control group, $\mathrm{P}<0.05$; ${ }^{\text {bexperimental group }}$ compared with the model group, $\mathrm{P}<0.05$. FEV, forced expiratory volume; FVC, forced vital capacity; PEF, peak expiratory flow.

Table III. Expression of specific mRNAs in rat lung tissues.

\begin{tabular}{lllllll}
\hline Group & $\mathrm{N}$ & TLR4 & MyD88 & TRAF-6 & LOX-1 & HMGB1 \\
\hline Control group & 10 & $1.00 \pm 0.20$ & $1.00 \pm 0.18$ & $1.00 \pm 0.21$ & $1.00 \pm 0.22$ & $1.00 \pm 0.19$ \\
Model group & 10 & $2.78 \pm 0.31^{\mathrm{a}}$ & $2.67 \pm 0.28^{\mathrm{a}}$ & $2.34 \pm 0.41^{\mathrm{a}}$ & $1.89 \pm 0.29^{\mathrm{a}}$ & $3.31 \pm 0.35^{\mathrm{a}}$ \\
Experimental group & 10 & $1.67 \pm 0.26^{\mathrm{a}, \mathrm{b}}$ & $1.98 \pm 0.25^{\mathrm{a}, \mathrm{b}}$ & $1.85 \pm 0.36^{\mathrm{a}, \mathrm{b}}$ & $1.38 \pm 0.37^{\mathrm{a}, \mathrm{b}}$ & $2.01 \pm 0.29^{\mathrm{a}, \mathrm{b}}$
\end{tabular}

${ }^{\mathrm{a}}$ Model group compared with the control group, $\mathrm{P}<0.05$; experimental group compared with the control group, $\mathrm{P}<0.05$; bexperimental group compared with the model group, $\mathrm{P}<0.05$. TLR4, Toll-like receptor 4; HMGB1, high mobility group box protein 1; MyD88, myeloid differentiation factor 88; TRAF-6, TNF receptor-associated factor 6; LOX-1, lectin-type oxidized LDL receptor 1.

Table IV. Expression of certain proteins in the rat lung tissues.

\begin{tabular}{|c|c|c|c|c|c|c|}
\hline Group & $\mathrm{N}$ & TLR4 & MyD88 & TRAF-6 & LOX-1 & HMGB 1 \\
\hline Control group & 10 & $0.82 \pm 0.11$ & $0.56 \pm 0.12$ & $0.58 \pm 0.14$ & $0.51 \pm 0.09$ & $0.79 \pm 0.14$ \\
\hline Model group & 10 & $1.21 \pm 0.12^{\mathrm{a}}$ & $0.73 \pm 0.11^{\mathrm{a}}$ & $0.76 \pm 0.13^{a}$ & $0.95 \pm 0.10^{\mathrm{a}}$ & $1.36 \pm 0.15^{\mathrm{a}}$ \\
\hline Experimental group & 10 & $0.93 \pm 0.10^{\mathrm{a}, \mathrm{b}}$ & $0.61 \pm 0.10^{\mathrm{a}, \mathrm{b}}$ & $0.62 \pm 0.10^{\mathrm{a}, \mathrm{b}}$ & $0.72 \pm 0.11^{\mathrm{a}, \mathrm{b}}$ & $1.04 \pm 0.13^{\mathrm{a}, \mathrm{b}}$ \\
\hline
\end{tabular}

${ }^{a}$ Model group compared with the control group, $\mathrm{P}<0.05$; experimental group compared with the control group, $\mathrm{P}<0.05$; bexperimental group compared with the model group, $\mathrm{P}<0.05$. TLR4, Toll-like receptor 4; HMGB1, high mobility group box protein 1; MyD88, myeloid differentiation factor 88; TRAF-6, TNF receptor-associated factor 6; LOX-1, lectin-type oxidized LDL receptor 1.

(FVC) were significantly lower in the model group compared with in the control group $(\mathrm{P}<0.05)$. In the experimental group, FEV and FVC were significantly increased compared with in the model group $(\mathrm{P}<0.05)$.

mRNA and protein expression of TLR4, MYD88, TRAF-6, LOX-1 and HMGB1 in lung tissues. The mRNA expression levels of TLR4, MyD88, TRAF-6, LOX-1 and HMGB1 were evaluated in the lung tissues of rats from each group. As depicted in the Table III, the mRNA expression levels of all genes were significantly increased in the model group compared with in the control group $(\mathrm{P}<0.05)$. In rats from the experimental group with ulinastatin treatment, the mRNA levels are significantly lower when compared with in the model group $(\mathrm{P}<0.05)$; however, they are significantly higher when compared with in the control group $(\mathrm{P}<0.05)$.

The western blot analyzes reveal a variation of protein expression levels similar to that of the mRNA expression levels (Fig. 1, Table IV). The protein expression levels of TLR4, MyD88, TRAF-6, LOX-1 and HMGB1 were greater in the model group compared with in the control group $(\mathrm{P}<0.05)$.
In the lung tissue of rats that received the ulinastatin treatment, the protein expression levels were significantly lower $(\mathrm{P}<0.05)$ compared with in the model rats, but remained higher in comparison with the control rats $(\mathrm{P}<0.05)$.

Correlation between the protein expression levels of TLR4 and HMGB1 in the rat lung tissues. Pearson's correlation analysis was conducted to analyze the correlation between TLR4 and HMGB1 protein expression levels in the lung tissue of the rats (Fig. 2). The results revealed that TLR4 and HMGB1 expression levels exhibit positive correlations in the control group $(\mathrm{r}=0.764, \mathrm{P}=0.010)$, model group $(\mathrm{r}=0.814, \mathrm{P}=0.004)$ and experimental group $(\mathrm{r}=0.805, \mathrm{P}=0.005)$.

Correlation between TLR4 and HMGB1 expression levels and the lung function of rats. Spearman's correlation analysis was conducted to analyze the correlation between the rat lung function index FEV, and TLR4 and HMGB1 protein expression levels (Fig. 3). The results reveal that there is a significant negative correlation between FEV, and TLR4 ( $\mathrm{r}=-0.845$, $\mathrm{P}<0.001)$ and HMGB1 expression levels $(\mathrm{r}=-0.820, \mathrm{P}<0.001)$. 


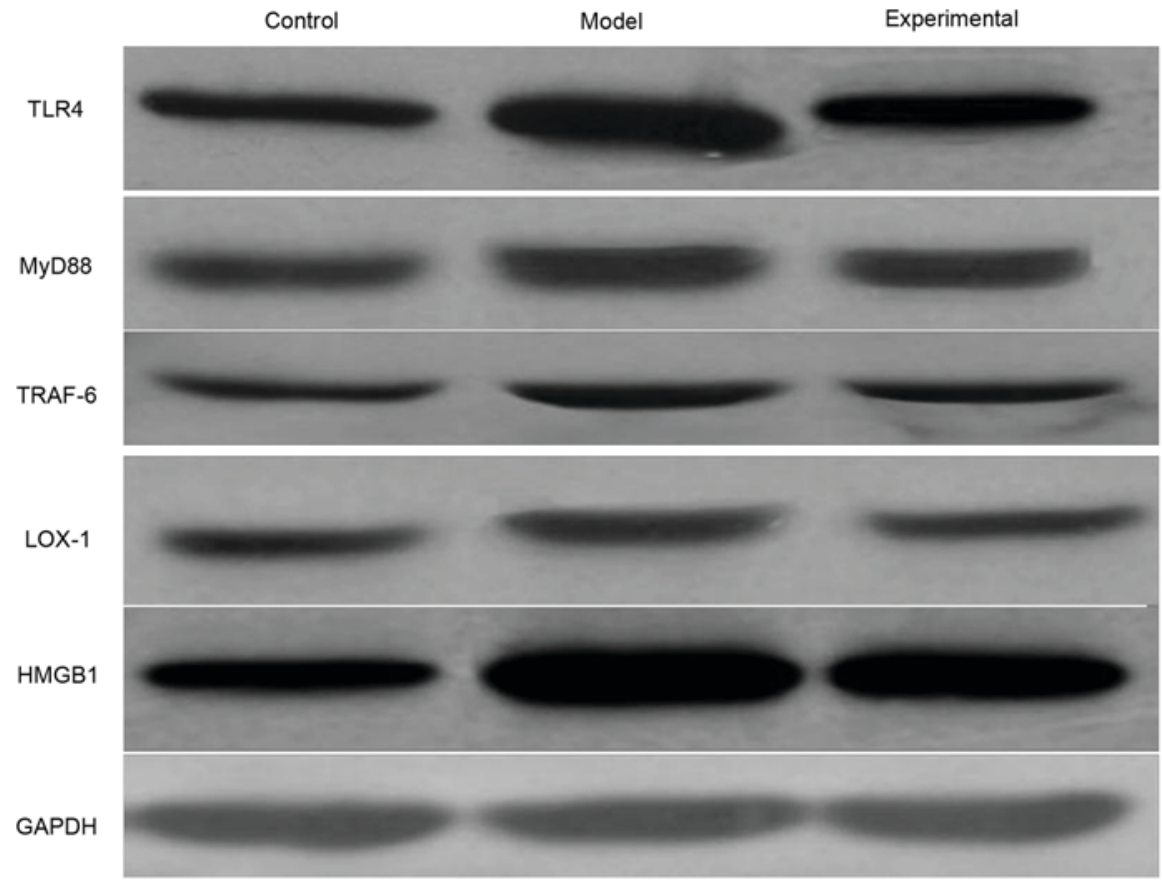

Figure 1. Protein expression levels of TLR4, MyD88, TRAF-6, LOX-1 and HMGB1 in the lung tissue of rats from the control, model and experimental groups. GAPDH was used as a loading control. TLR4, Toll-like receptor 4; MyD88, myeloid differentiation factor 88; TRAF-6, TNF receptor-associated factor 6; LOX-1, lectin-type oxidized LDL receptor 1; HMGB1, high mobility group box protein 1.
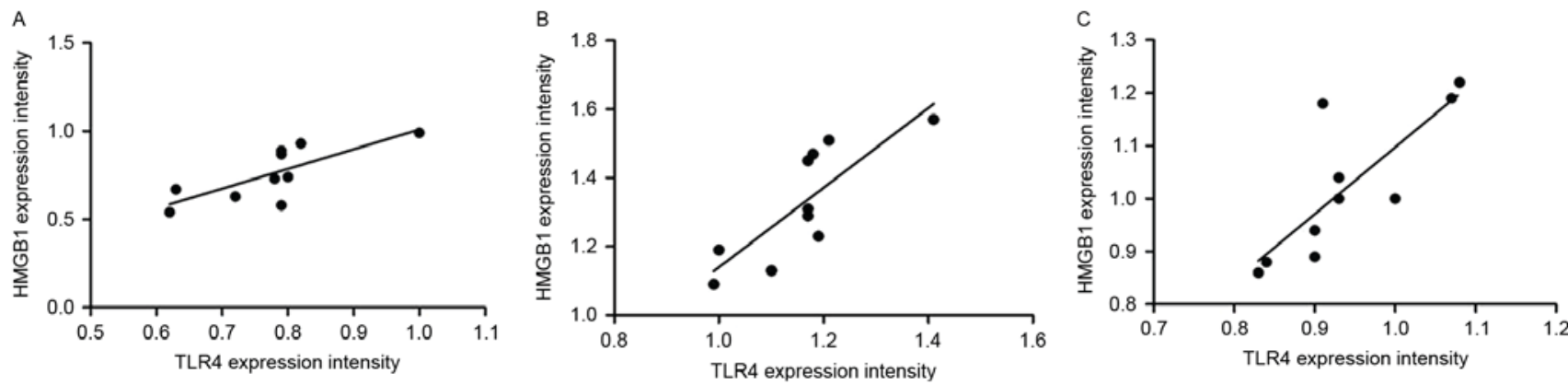

Figure 2. Correlation between the protein expression levels of toll-like receptor 4 and high mobility group box protein 1 in the lung tissue of rats from (A) the control group, (B) the model group and (C) the experimental group. TLR4, Toll-like receptor 4; HMGB1, high mobility group box protein 1.
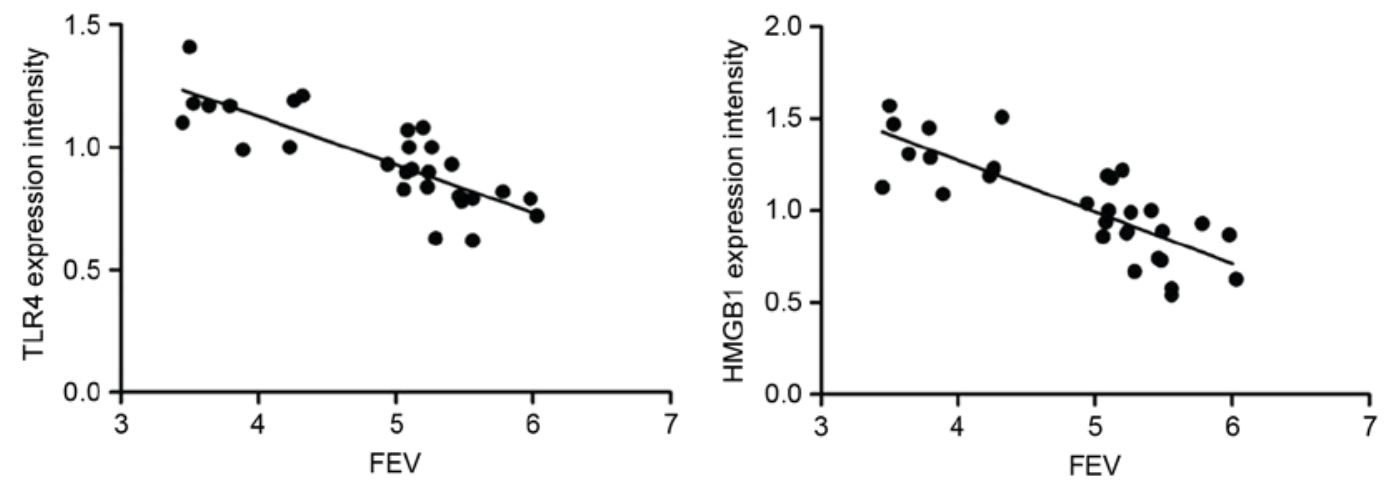

Figure 3. Correlation between the forced expiratory volume/sec and the protein expression levels of toll-like receptor 4 and high mobility group box protein 1 . TLR4, Toll-like receptor 4; HMGB1, high mobility group box protein 1; FEV, forced expiratory volume/sec.

\section{Discussion}

Currently, it is generally considered that COPD is characterized by chronic inflammation in the airway, lung parenchyma and pulmonary vascular vessels (21). The activated inflammatory cells have the ability to release numerous 
inflammatory mediators, which can damage the lung tissue structure and/or promote an inflammatory reaction (22). Therefore, the release of inflammatory mediators serves an important role in the occurrence and development of COPD; in addition, protease/anti-protease imbalance serves an important role in the pathogenesis of COPD (23). Previous studies have revealed that ulinastatin, a type of broad-spectrum protease inhibitor, can reduce tissue damage by inhibiting the release of inflammatory mediators, as observed in acute kidney injury (24), acute pancreatitis (25) and acute lung injury $(7,26)$; however, there are very limited reports on the treatment of COPD with ulinastatin. Therefore, in the present study COPD rat models were established, and underwent ulinastatin treatment, to determine whether ulinastatin had an effect on COPD; which may eventually lead to the elucidation of the underlying disease mechanism.

Pulmonary function tests are the most commonly used clinical indicators to assess COPD lesions, and can confirm the nature and extent of lung injury; FEV, FEV/FVC and peak expiratory flow (PEF) are important clinical indicators of lung function, and can be used to monitor the extent of COPD, and thus guide the selection of treatment $(27,28)$. The present study used the pulmonary function test indicators to evaluate the efficacy of ulinastatin. The results revealed that after the treatment with ulinastatin, the FEV0.3, FVC, FEV0.3/FVC and PEF indexes in the experimental group were significantly higher than those in the model group; this suggests that the rat lung function had improved to a certain extent, and, therefore, that ulinastatin had a protective effect on the lungs of COPD rats. Ulinastatin exerts its inhibitory effect on the activity of various proteases, and carbohydrate and lipid hydrolases, while simultaneously inhibiting the production of oxygen free radicals, thus reducing the oxidative damage to and inflammatory reactions of lung tissues. As HMGB1 is an important cytokine for initiating and maintaining inflammatory reactions, the expressions of HMGB1 and TLR4 signaling pathway-associated molecules, TLR4, MyD88, TRAF-6 and LOX-1, were detected. The results revealed that, compared with in the control group, the mRNA and protein expression levels of TLR4, MyD88, TRAF-6, LOX-1 and HMGB1 were significantly higher in the model group, suggesting that the HMGB1/TLR4 signaling pathway is involved in the occurrence of COPD. After the treatment with ulinastatin, the expression levels of TLR4, MyD88, TRAF-6, LOX-1 and HMGB1 mRNA and protein were significantly decreased in the experimental group, compared with in the model group, and FEV exhibited a significant negative correlation with TLR4 and HMGB1 expression levels. These suggests that the protective effect of ulinastatin on the lung of the COPD rat is associated with inhibiting the expression of molecules associated with the HMGB1/TLR4 signaling pathway. In a previous study, Ko et al (29) reported that HMGB1 was associated with the occurrence of COPD, and that the serum expression level of HMGB1 had a significant negative correlation with the FEV1/FVC ratio. Kanazawa et al (30) revealed that the HMGB1 content in the epithelial lining fluid of patients with COPD was notably higher than in the healthy control population. The study by Gangemi et al (15) demonstrated that the content of the inflammatory factor HMGB1 in the peripheral blood of patients with COPD was notably elevated. In the present study, the HMGB1 expression in the lung tissues of the COPD model rats was significantly higher than in the control group, indicating that HMGB1 may participate in promoting the onset of COPD. The data are consistent with the studies conducted by Kanazawa et al (30) and Gangemi et al (15). Furthermore, the study by Li et al (31) determined that, compared with in the healthy control population, TRL4 expression in the bronchoalveolar lavage fluid of patients with COPD was significantly high. In the present study, HMGB1 expression was significantly higher in the lung tissues of the COPD model rats, compared with in the control rats, indicating that TLR4 participates in the onset of COPD; these results were similar to those reported by $\mathrm{Li}$ et al (31).

Simvastatin is closely associated with the treatment mechanism of COPD and the inhibition of TLR4 expression (32), and isothiocyanate serves an anti-inflammatory role in the treatment of COPD by inhibiting the expression of molecules associated with the TLR4/MyD88 signaling pathway (33); however, there are no associated reports on the treatment of COPD rat with ulinastatin, to the best of our knowledge.

The pathogenesis of COPD is complex, along with the treatment mechanism of ulinastatin in COPD $(34,35)$. In the present study, the focus was on the HMGB1/TLR4 signaling pathway, and the conclusion is that the protective effect of ulinastatin on the lungs of COPD rats may be associated with changes in the HMGB1/TLR4 signaling pathway; however, what it discloses is only the tip of the iceberg in its complex action mechanism. For the better application of ulinastatin in the clinical treatment of COPD, further exploration of the mechanism of action is required.

\section{Acknowledgements}

The authors would like to thank Dr. Daijiao Yi (Department of Respiratory Medicine, The Second People's Hospotial of Hunan Province, Hunan, China) for their help with animal feeding and specimen processing and Dr. Zhuolan Chen (The Medical Ultrasound, Hunan Children's Hosptial, Hunan, China) for her help in data collection.

\section{Funding}

No funding was received.

\section{Availability of data and materials}

The datasets used and analyzed during the current study are available from the corresponding author on reasonable request.

\section{Authors' contributions}

WL was responsible for the acquisition of data in animal experiments and drafting the manuscript. WZ was responsible for the statistical analysis, writing and revision of the paper. $\mathrm{ZL}$ was responsible for analysis and interpretation of data in animal experiments and revising the manuscript. SC was responsible for the design and modification of experimental protocols, statistical analysis and thesis revision. 


\section{Ethics approval and consent to participate}

The experimental program in this study was examined and ethically approved by the Institute Research Ethics Committee at Hunan Provincial People's Hospital (Changsha, China).

\section{Patient consent for publication}

Not applicable.

\section{Competing interests}

The authors declare they have no competing interests.

\section{References}

1. Doucet M, Rochette L and Hamel D: Incidence, prevalence, and mortality trends in chronic obstructive pulmonary disease over 2001 to 2011: A public health point of view of the burden. Can Respir J 2016: 7518287, 2016.

2. Pauwels RA and Rabe KF: Burden and clinical features of chronic obstructive pulmonary disease (COPD). Lancet 364: 613-620, 2004

3. Bao H, Fang L and Wang L: Prevalence of chronic obstructive pulmonary disease among community population aged $\geq 40$ in China: A meta-analysis on studies published between 1990 and 2014. Zhonghua Liu Xing Bing Xue Za Zhi 37: 119-124, 2016 (In Chinese).

4. Zhong N, Wang C, Yao W, Chen P, Kang J, Huang S, Chen B, Wang C, Ni D, Zhou Y, et al: Prevalence of chronic obstructive pulmonary disease in China: A large, population-based survey. Am J Respir Crit Care Med 176: 753-760, 2007.

5. Vestbo J,Hurd SS, Agusti AG,Jones PW, Vogelmeier C, Anzueto A, Barnes PJ, Fabbri LM, Martinez FJ, Nishimura M, et al: Global strategy for the diagnosis, management, and prevention of chronic obstructive pulmonary disease: GOLD executive summary. Am J Respir Crit Care Med 187: 347-365, 2013.

6. Fang Y, Xu P, Gu C, Fu XJ, Yu WR and Yao M: Ulinastatin improves pulmonary function in severe burn-induced acute lung injury by attenuating inflammatory response. J Trauma 71: $1297-1304,2011$

7. Li W, Qiu X, Jiang H, Zhi Y, Fu J and Liu J: Ulinastatin inhibits the inflammation of LPS-induced acute lung injury in mice via regulation of AMPK/NF- $\kappa$ B pathway. Int Immunopharmacol 29: 560-567, 2015

8. Wang SY, Li ZJ, Wang X, Li WF and Lin ZF: Effect of ulinastatin on HMGB1 expression in rats with acute lung injury induced by sepsis. Genet Mol Res 14: 4344-4353, 2015.

9. Zhang Y, Qiu X, Zhou G, Liu Z, Chang N and Jia C: Early effects of ulinastatin by aerosol inhalation on rabbits with lipopolysaccharide-induced acute lung injury. Zhonghua Shao Shang Za Zhi 30: 203-207, 2014 (In Chinese).

10. Wang N, Liu X, Zheng X, Cao H, Wei G, Zhu Y, Fan S, Zhou H and Zheng J: Ulinastatin is a novel candidate drug for sepsis and secondary acute lung injury, evidence from an optimized CLP rat model. Int Immunopharmacol 17: 799-807, 2013.

11. Dange RB, Agarwal D, Teruyama R and Francis J: Toll-like receptor 4 inhibition within the paraventricular nucleus attenuates blood pressure and inflammatory response in a genetic model of hypertension. J Neuroinflammation 12: 31, 2015.

12. Wang H, Bloom O, Zhang M, Vishnubhakat JM, Ombrellino M, Che J, Frazier A, Yang H, Ivanova S, Borovikova L, et al: HMG-1 as a late mediator of endotoxin lethality in mice. Science 285 : 248-251, 1999.

13. Li J,Hu C, Yao Y and Yang H: Effects of ulinastatin on immune function of spleen in severely burned rats and its mechanism. Zhonghua Shao Shang Za Zhi 32: 266-271, 2016 (In Chinese).

14. Tong Y, Tang Z, Yang T, Yang Y, Yang L, Shen W and Chen W: Ulinastatin preconditioning attenuates inflammatory reaction of hepatic ischemia reperfusion injury in rats via high mobility group box 1(HMGB1) inhibition. Int J Med Sci 11: 337-343, 2014

15. Gangemi S, Casciaro M, Trapani G, Quartuccio S, Navarra M Pioggia G and Imbalzano E: Association between HMGB1 and COPD: A systematic review. Mediators Inflamm 2015: 164913, 2015.
16. Chen Y, Huang XJ, Yu N, Xie Y, Zhang K, Wen F, Liu H and Di Q: HMGB1 contributes to the expression of P-glycoprotein in mouse epileptic brain through toll-like receptor 4 and receptor for advanced glycation end products. PLoS One 10: e140918, 2015.

17. Li G, Wu X, Yang L, He Y,Liu Y,Jin X and Yuan H: TLR4-mediated $\mathrm{NF}-\kappa \mathrm{B}$ signaling pathway mediates HMGB1-induced pancreatic injury in mice with severe acute pancreatitis. Int J Mol Med 37: 99-107, 2016.

18. Cheng Y, Wang D, Wang B, Li H, Xiong J, Xu S, Chen Q, Tao K, Yang X, Zhu Y and He S: HMGB1 translocation and release mediate cigarette smoke-induced pulmonary inflammation in mice through a TLR4/MyD88-dependent signaling pathway. Mol Biol Cell 28: 201-209, 2017.

19. Lai CH, Wang KC, Lee FT, Tsai HW, Ma CY, Cheng TL, Chang BI, Yang YJ, Shi GY and Wu HL: Toll-like receptor 4 is essential in the development of abdominal aortic aneurysm. PLoS One 11: e146565, 2016.

20. Livak KJ and Schmittgen TD: Analysis of relative gene expression data using real-time quantitative PCR and the 2(-Delta Delta C(T)) method. Methods 25: 402-408, 2001

21. Reséndiz-Hernández JM and Falfán-Valencia R: Genetic polymorphisms and their involvement in the regulation of the inflammatory response in asthma and COPD. Adv Clin Exp Med 27: 125-133, 2018.

22. Huckle AW, Fairclough LC and Todd I: Prophylactic antibiotic use in COPD and the potential anti-inflammatory activities of antibiotics Respir Care 63: 609-619, 2018.

23. Yamasaki K and Eeden S: Lung macrophage phenotypes and functional responses: Role in the pathogenesis of COPD. Int J Mol Sci 19: pii: E582, 2018.

24. Wan X, Xie X, Gendoo Y, Chen X, Ji X and Cao C: Ulinastatin administration is associated with a lower incidence of acute kidney injury after cardiac surgery: A propensity score matched study. Crit Care 20: 42, 2016.

25. Zhang C, Wang Y, Fu W, Zhang W, Wang T and Qin H: A meta-analysis on the effect of ulinastatin on serum levels of $\mathrm{C}$-reactive protein, interleukin 6 , and tumor necrosis factor alpha in Asian patients with acute pancreatitis. Genet Test Mol Biomarkers 20: 118-124, 2016.

26. Sun R, Li Y, Chen W, Zhang F and Li T: Total ginsenosides synergize with ulinastatin against septic acute lung injury and acute respiratory distress syndrome. Int J Clin Exp Pathol 8: 7385-7390, 2015.

27. Yanagisawa $S$ and Ichinose M: Definition and diagnosis of asthma-COPD overlap (ACO). Allergol Int 67: 172-178, 2018.

28. Twigg MJ and Wright DJ: Community pharmacy COPD services: What do researchers and policy makers need to know? Integr Pharm Res Pract 6: 53-59, 2017.

29. Ko HK, Hsu WH, Hsieh CC, Lien TC, Lee TS and Kou YR: High expression of high-mobility group box 1 in the blood and lungs is associated with the development of chronic obstructive pulmonary disease in smokers. Respirology 19: 253-261, 2014.

30. Kanazawa H, Tochino Y, Asai K, Ichimaru Y, Watanabe T and Hirata K: Validity of HMGB1 measurement in epithelial lining fluid in patients with COPD. Eur J Clin Invest 42: 419-426, 2012.

31. Li H, Yang T, Li FY, Ning Q and Sun ZM: TLR4 overexpression inhibits endothelial PAS domain-containing protein 1 expression in the lower respiratory tract of patients with chronic COPD. Cell Physiol Biochem 39: 685-692, 2016.

32. Wang S, Xiong L, Deng X, Ren W, Zhu C, Li C and Zhou Q: Effects of simvastatin on airway inflammation and airway mucus hypersecretion in rats with chronic obstructive pulmonary disease. Zhonghua Yi Xue Za Zhi 95: 1726-1730, 2015 (In Chinese).

33. Zeng X, Liu X, Bao H, Zhang Y, Wang X, Shi K and Pang Q: Effects of sulforaphane on Toll-like receptor 4/myeloid differentiation factor 88 pathway of monocyte-derived macrophages from patients with chronic obstructive pulmonary disease. Zhonghua Jie He He Hu Xi Za Zhi 37: 250-254, 2014 (In Chinese).

34. Wang J, Wu A and Wu Y: Endothelial glycocalyx layer: A possible therapeutic target for acute lung injury during lung resection. Biomed Res Int 2017: 5969657, 2017.

35. Liu W and Chai JK: Influences of ulinastatin on acute lung injury and time phase changes of coagulation parameters in rats with burn-blast combined injuries. Zhonghua Shao Shang Za Zhi 34: 32-39, 2018 (In Chinese). 